\title{
Estimation of botulinum toxin type A efficacy on spasticity and functional outcome in children with spastic cerebral palsy
}

\author{
Hristina Colovic ${ }^{\mathrm{a}}$, Lidija Dimitrijevic ${ }^{\mathrm{a}, \mathrm{b}}$, Ivona Stankovic ${ }^{\mathrm{a}, \mathrm{b}}$, Dejan Nikolicc, Dragana Radovic-Janosevic ${ }^{\mathrm{b}, \mathrm{d}}$
}

\begin{abstract}
Aim. We evaluated the effects of botulinum toxin type A (BTA) - abobotulinumtoxinA on passive motion resistance (PMR) values of lower limbs affected muscles and on the functional motor status in children with spastic cerebral palsy $(C P)$.

Methods. In Group I (28 lower limbs with spastic muscles), and in Group II (14 lower limbs with dynamic spastic equinus) BTA was administered. Physical therapy was prescribed for 16 weeks. We estimated PMR using the Modified Ashworth Scale. Achieved functional motor level was evaluated by Gross Motor Function Classification System (GMFCS) and Gross Motor Function Measure (GMFM). Parameters were assessed before treatment and after 3,8,16 weeks and 6 months respectively.

Results. In Group I, PMR was significantly lower for hip adductors and knee extensors over 3-16 weeks, and for ankle joint extensors in both groups.

There were significant differences for both groups in frequencies of GMFCS values after 16 weeks from BTA application. There was a significant increase in GMFM scores after 8 and 16 weeks from BTA application in both groups of patients. Conclusions. BTA treatment in CP children is followed by reduction in PMR values and improvement in functional motor status.
\end{abstract}

Key words: cerebral palsy, spasticity, children, botulinum toxin, physical, therapy

Received: September 30, 2011; Accepted with revision: January 27, 2012; Available online: February 17, 2012 http://dx.doi.org/10.5507/bp.2012.017

${ }^{a}$ Clinic for Physical Therapy and Rehabilitation, Clinical Centre of Nis, Nis, Serbia

${ }^{b}$ Faculty of Medicine, University of Nis, Nis, Serbia

'Physical Medicine and Rehabilitation, University Children's Hospital, Belgrade, Serbia

${ }^{d G y n e c o l o g y}$ and Obstetrics Clinic, clinical Centre of Nis, Nis, Serbia

Corresponding author: Hristina Colovic, e-mail: ninacol40@ymail.com

\section{INTRODUCTION}

Cerebral palsy $(\mathrm{CP})$ is a group of developmental disorders of movement and posture, causing activity limitation, that are attributed to a non-progressive disturbances in the developing fetal or infant brain. The motor disorders of cerebral palsy are often accompanied by disturbances of sensation, cognition, communication, perception, and/ or behavior, and/or by a seizure disorder ${ }^{1}$. The most frequent presentation of neurological impairment in $\mathrm{CP}$ is spasticity with most pronounced effect on skeletal muscles $(70-80 \%)$, where heterogeneity of clinical phenotypes is the dominant characteristic ${ }^{2,3}$. Affected muscles usually present with fewer myofibrils and their decreased longitudinal length. Studies have demonstrated that decrease in the longitudinal length of myofibrils of $50 \%$ leads to the onset of contractures and fixed deformities of the skeletal-joint system ${ }^{47}$. In the spastic type of CP, contractures are present in early stages. Therefore, even though spasticity is primarily present, the majority of children have combined clinical presentation of spasm and contracture ${ }^{8}$. Regarding the therapy approach, it is important to distinguish 2 types of contractures: dynamic (in younger children, where reduction in joint movement range is due to the spasm of affected muscles) and fixed (in older children with limitation in joint movement range) $\left(\right.$ ref. $\left.^{8}\right)$. The therapy approach for spastic muscles and dynamic contractures include application of botulinum toxin (BT), physical therapy and orthoses ${ }^{2}$. In human medicine, BT is most frequently used as BT type A (BTA) that is commercially available as Dysport ${ }^{\circledR}$ (Ipsen Ltd, Slough, UK) (abobotulinumtoxinA - ABO), BOTOX ${ }^{\circledR}$ (Allergan Pty Ltd) (onabotulinumtoxinA - ONA) and Xeomin ${ }^{\circledR}$ (Merz Pharmaceuticals) (ref. ${ }^{2,9,10}$ ).

The consensus regarding the application of BTA in the therapy of lower limbs spasticity in children with spastic type of CP is based on analyses of numerous reports and studies from the International Committee for BTA therapy ${ }^{2}$. It is noticed that BTA injection is an effective treatment for spasticity of lower limbs in CP patients and should be combined with physical therapy and orthoses. Previous reports state that higher quality of outcome involves accurate measures of quantitative and qualitative parameters. Since, there is no single unit consolidating both parameters it is recommended that outcome measures should include at least one objective parameter that refers to local response to BTA application and at least one functional parameter ${ }^{2,11}$. Therefore, the aim of our study was to evaluate the effects of BTA - ABO application on passive motion resistance (PMR) values of af- 
fected muscles on lower limbs and on functional motoric status in children with spastic type of CP.

\section{MATERIAL AND METHODS}

The prospective clinical study included 27 children, aged between 2-6 with unilateral or bilateral types of spastic cerebral palsy. The proposed study methodology and evaluation parameters were approved by the Institutional Review Board of Faculty of Medicine and carried out according to the principals of good clinical practice. The administration of BTA was done by a board certified Physiatrist. Initial clinical screening for prior inclusion in the study and follow-up was done by board certified Physiatrists, among them with sub-specialty in pediatric rehabilitation and extensive experience in neurological rehabilitation. Complete hetero-anamnesis was taken from parents or legal guardians of eligible participants, and complete clinical and diagnostic tests were performed in order to establish treatment protocol. The BTA was administered into the spastic muscles of lower limbs. The criteria for inclusion of the evaluated subjects in the study were: dynamic contractures of lower limbs with inadequate response to physical therapy; patients capable of walking with or without support; patients who were regularly and continuously involved in re-habilitation. Criteria for exclusion of evaluated subjects from the study were: presence of fixed contractures of lower limbs joints; significant difference in length between lower limbs $(>5 \mathrm{~cm})$; apparent muscular atrophy of lower limbs; surgical indications; preformed surgical intervention on the foot, ankle joint and leg; previously administered injection with alcohol medium in the muscle that was to be treated in the study; non regular rehabilitation attendance. The parents or legal guardians of the patients that were included in the study were informed about the protocol and consent was obtained prior to inclusion. For application of BTA, abobotulinumtoxinA ( $\mathrm{ABO}$ ) was used. One ampoule of BTA that was administered and consisted of 500 international units (I.U.). dissolved just before application in $2.5 \mathrm{ml}$ of sterile $0.9 \%$ Sodium chloride $(\mathrm{NaCl})$ solution. Total drug dosage was distributed to several regions in the lower limbs muscles, according to the degree of the spasticity. Two groups were analyzed: Group I consisted of 28 evaluated lower limbs, where spastic adductor muscles, hamstrings (semimembranosus and semitendinosus muscles), and medial and lateral heads of gastrocnemius muscle were treated with the application of the BTA into the spastic muscle. Group II consisted of 14 evaluated lower limbs with dynamic spastic equinus of the foot, which was treated by the BTA application in the both heads (medial and lateral) of gastrocnemius muscle.Palpation was used to assess the place of BTA administration. For each application site defined dosage of BTA was prepared in a plastic syringe $1 \mathrm{~cm}^{3}$ and for intramuscular infiltration $\mathrm{G}$ 24-27 needles of $25-40 \mathrm{~mm}$ in length were used. Total drug dosage was calculated according to the patient's weight. For children with the unilateral form, when the drug was administered into one leg, the dose was 10 I.U./kg, while for children with the bilateral form, where the drug was administered into both legs, total dosage was 20 I.U./kg. According to the board certified physician's estimation, one hour before drug administration, for the purpose of patient's sedation, diazepam suppositories were used. Physical therapy protocol was individually prescribed and assessed, and refers to an identical program for evaluated subjects that were included in the study: parafino therapy; kinesiotherapy (exercises to increase movement range, elongation of muscles with reduced length, strengthening of the antagonists, balance and coordination exercises, exercises for the correction of improperly developed motoric functions: sitting, crawling, walking and for the stimulation of non developed motor functions); occupational and functional therapy; and application of adequate orthoses for the correction of foot equinus deformity. Physical therapy was initiated 5 days following BTA administration, 3 times a week for 16 weeks and for a duration of 45-60 min. Effects of BTA application and performed re-habilitation were assessed by follow-up and muscles PMR analysis on affected leg and by functional motoric status estimation. These parameters were measured five times: before treatment, and 3 weeks, 8 weeks, 16 weeks and 6 months after the beginning of the treatment. Passive motion resistance was estimated according to the Modified Ashworth Scale (MAS) (ref. ${ }^{12,13}$ ). To ensure reliability of results, 3 physiotherapists with extensive experience in pediatric rehabilitation (more than 15 years) under the supervision of board certified Physiatrist with sub-specialty in pediatric rehabilitation preformed measurement, and results gained on same day of evaluation were compared. For the estimation of achieved functional motoric level of evaluated patients, we applied Gross Motor Function Classification System (GMFCS) - the classification system for the estimation of adopted rough motoric functions in children with $\mathrm{CP}$ (ref. ${ }^{14}$ ). To measure the change in gross motor function during the follow-up of evaluated patients with $\mathrm{CP}$ we used Gross Motor Function Measure (GMFM) score. We implemented the GMFM-88 score that is composed of 5 determinants with each item having a range from $0-3\left(\right.$ ref. $\left.{ }^{15}\right)$. The physiotherapists with expertise in pediatric developmental rehabilitation preformed evaluation of GMFCS and GMFM under the supervision of board certified Physiatrist.Data were presented as arithmetic mean (X), standard deviation (SD), minimal (Min) and maximal (Max) values and 95\% confidence interval (95\% CI). Categorical variables were presented as frequencies. Student's t-test for independent samples was used to test differences between mean values of different groups of patients, and in the cases where distribution of parameters showed deviation from normal (estimated by Shapiro-Wilk test) we used Mann-Whitney test. Student's t-test for dependent samples was used to test presence of statistical difference in the groups comparing evaluated parameters in tested intervals, and in the cases were distribution of parameters showed deviation from normal we preformed Wilcoxon Signed ranks test. Comparison of frequency distributions was done by Pearson $\chi 2$ test. Statistical significance was set at $P<0.05$. 


\section{RESULTS}

There were 17 (62.96\%) male and 10 (37.04\%) female participants diagnosed as spastic CP. Group I included 16 children while Group II included 11 patients with the spastic type of CP. The unilateral form was described in $12(44.44 \%)$ patients while bilateral in 15 (55.56\%) participants with CP. Shapiro-Wilk test determined normal distribution of further parameters: age, body weight (BW), total drug dosage and drug dosage regarding BW (I.U./ kg) (Table 1).

The average values for gender and laterality of $\mathrm{CP}$ (unilateral or bilateral) are given in Table 1. The average age of the participants was 4.12 SD 0.97 years, where the youngest was 2 years and 9 months, while the oldest was 6 years. Average BW was 18.30 SD $4.44 \mathrm{~kg}$ eranding from 11 to $30 \mathrm{~kg}$. Average drug dosage per participant was 237.78 SD 109.94 I.U., range from 100 I.U. to 480 I.U. Average drug dosage regarding participants BW (I.U./kg) was $12.89 \mathrm{SD} 4.70$ I.U. $/ \mathrm{kg}$ range interval between 8.33 to 20.83 I.U./kg. During the study in 3 patients symptoms of upper respiratory tract infection appeared after 2 weeks of BTA application. Degree of passive motion resistance was determined according to MAS. In Group I it is shown that lower values of PMR degree are more frequent regarding the estimation of hip adductors and for PMR of knee extensors at 3, 8 and 16 weeks after the BTA treatment when compared with initial values $(P<0.001)$ (Table 2$)$.

However, there was no significant difference between the evaluated values of PMR degree before treatment and after 6 months (Table 2). Regarding the PMR degree estimation for ankle joint extensors in both groups (Group I and Group II), lower values of such parameters were significantly more frequent at 3,8 and 16 weeks respectively after the BTA application versus initial values before treatment $(P<0.001)$ (Table 3$)$. After the 6 months we found no significant differences in values regarding degree of ankle joint extensors PMR degree when they were compared with the values before BTA but we found that lower values were more frequent (Table 3 ).

We showed that there were significant differences in frequencies of GMFCS values only after 16 weeks from the BTA application, both in Group I and Group II, compared with the values before treatment initiation $(P<0.001)$ (Table 4). GMFCS values did not significantly differ after 3 and 8 weeks or 6 months of the BTA treatment beginning versus the values before therapy (Table 4 ). When the GMFCS values were compared between groups, we found statistically significant difference in GMFCS values after 8 and 16 weeks as well as 6 months of the BTA application $(P<0.001)$, generally due to the better functional levels of Group II. When subjects were analyzed as one sample, GMFCS values significantly differed after 8 weeks $(P<0.05)$ and 16 weeks $(P<0.001)$ of BTA application versus initial values before treatment (Table 4).

In Table 5, we presented the total GMFM score in patients before and after BTA in both groups. Mean values of total GMFM score in patients from Group I significantly differ (higher) after 8 weeks $(P<0.05)$ versus those at the beginning of treatment, and highly significantly different (higher) after 16 weeks $(P<0.01)$ from the values at the beginning of therapy. The same applied to patients from Group II.

Table 1. Evaluated parameters and statistical presentation regarding gender and laterality of $\mathrm{CP}$ (unilateral or bilateral).

\begin{tabular}{|c|c|c|c|c|c|c|c|}
\hline & & & $\begin{array}{l}\text { Number of } \\
\text { participants }\end{array}$ & Mean value and SD & $95 \% \mathrm{CI}$ & $\begin{array}{l}\text { Minimal } \\
\text { value }\end{array}$ & $\begin{array}{c}\text { Maximal } \\
\text { value }\end{array}$ \\
\hline \multirow[t]{4}{*}{ Age (years) } & \multirow[t]{2}{*}{ Gender } & Male & 17 & $4.23 \mathrm{SD} 1.05$ & $3.69-4.77$ & 2.90 & 6.00 \\
\hline & & Female & 10 & $3.95 \mathrm{SD} 0.84$ & $3.34-4.55$ & 2.75 & 5.20 \\
\hline & \multirow[t]{2}{*}{ CP laterality } & Unilateral & 12 & 4.19 SD 1.15 & $3.46-4.92$ & 2.75 & 6.00 \\
\hline & & Bilateral & 15 & $4.07 \mathrm{SD} 0.85$ & $3.60-4.54$ & 2.90 & 6.00 \\
\hline \multirow{4}{*}{$\begin{array}{l}\text { Body mass } \\
(\mathrm{kg})\end{array}$} & \multirow[t]{2}{*}{ Gender } & Male & 17 & 18.47 SD 4.86 & $15.97-20.97$ & 12.00 & 30.00 \\
\hline & & Female & 10 & 18.00 SD 3.83 & $15.26-20.74$ & 11.00 & 24.00 \\
\hline & \multirow[t]{2}{*}{ CP laterality } & Unilateral & 12 & 18.33 SD 5.48 & $14.85-21.82$ & 11.00 & 30.00 \\
\hline & & Bilateral & 15 & 18.27 SD 3.59 & $16.28-20.26$ & 12.00 & 24.00 \\
\hline \multirow{4}{*}{$\begin{array}{l}\text { Total dosage } \\
\text { (I.J.) }\end{array}$} & \multirow[t]{2}{*}{ Gender } & Male & 17 & 233.53 SD 99.18 & $182.54-284.52$ & 120.00 & 450.00 \\
\hline & & Female & 10 & 245.00 SD 131.68 & $150.80-339.20$ & 100.00 & 480.00 \\
\hline & \multirow[t]{2}{*}{ CP laterality } & Unilateral & 12 & 179.17 SD 45.82 & $150.06-208.28$ & 100.00 & 250.00 \\
\hline & & Bilateral & 15 & *284.67 SD 124.49 & $215.73-353.61$ & 140.00 & 480.00 \\
\hline \multirow{4}{*}{$\begin{array}{l}\text { Total dosage } \\
\text { per weight } \\
\text { unit (I.J./kg) }\end{array}$} & \multirow[t]{2}{*}{ Gender } & Male & 17 & 12.82 SD 4.80 & $10.35-15.29$ & 8.33 & 20.83 \\
\hline & & Female & 10 & 13.02 SD 4.79 & $9.59-16.44$ & 8.82 & 20.00 \\
\hline & \multirow[t]{2}{*}{ CP laterality } & Unilateral & 12 & 9.90 SD 1.37 & $9.03-10.78$ & 8.33 & 13.33 \\
\hline & & Bilateral & 15 & **15.28 SD 5.08 & 12.47-18.09 & 8.82 & 20.83 \\
\hline
\end{tabular}

$P<0.05, * * P<0.01$ (Mann-Whitney U test)

CP - Cerebral palsy 
Table 2. Evaluation of PMR level frequencies for hip adductors and knee extensors according to MAS before and after BTA application.

\begin{tabular}{|c|c|c|c|c|c|c|c|c|c|c|}
\hline \multirow[b]{3}{*}{$\begin{array}{l}\text { PMR } \\
\text { level }\end{array}$} & \multirow{2}{*}{\multicolumn{2}{|c|}{$\begin{array}{l}\text { Before treatment } \\
\text { (Group I) }\end{array}$}} & \multicolumn{8}{|c|}{ After application of BTA (Group I) } \\
\hline & & & \multicolumn{2}{|c|}{3 weeks } & \multicolumn{2}{|c|}{8 weeks } & \multicolumn{2}{|c|}{16 weeks } & \multicolumn{2}{|c|}{6 months } \\
\hline & 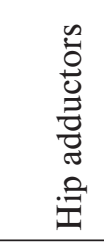 & 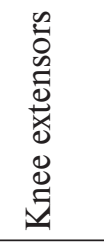 & 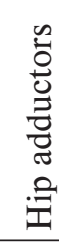 & 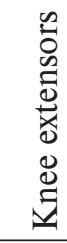 & 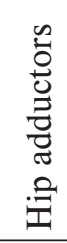 & 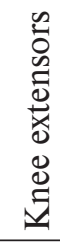 & 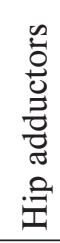 & 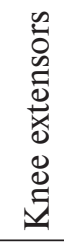 & 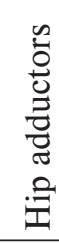 & 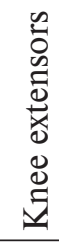 \\
\hline 0 & 0 & 0 & 17 & 22 & 23 & 24 & 1 & 2 & 0 & 0 \\
\hline 1 & 1 & 4 & 9 & 4 & 5 & 4 & 4 & 8 & 1 & 4 \\
\hline $1+$ & 1 & 1 & 2 & 2 & 0 & 0 & 4 & 10 & 1 & 1 \\
\hline 2 & 14 & 14 & 0 & 0 & 0 & 0 & 16 & 8 & 17 & 16 \\
\hline 3 & 12 & 9 & 0 & 0 & 0 & 0 & 2 & 0 & 9 & 7 \\
\hline 4 & 0 & 0 & 0 & 0 & 0 & 0 & 0 & 0 & 0 & 0 \\
\hline Total & 28 & 28 & 28 & 28 & 28 & 28 & 28 & 28 & 28 & 28 \\
\hline $\begin{array}{l}\text { Pearson } \\
\left(\chi^{2}\right) \text { test }\end{array}$ & $\begin{array}{l}\text { Signif } \\
\text { fore an } \\
\text { ment) }\end{array}$ & r treat- & * & * & * & * & * & * & ns & ns \\
\hline
\end{tabular}

ns $-P>0.05 ;{ }^{*} P<0.01$

PMR-Passive Motion Resistance; MAS - Modified Ashworth Scale; BTA - Botulinum toxin type A

Table 3. Evaluation of PMR for ankle joint extensors according to MAS before and after BTA application.

\begin{tabular}{|c|c|c|c|c|c|c|c|c|c|c|}
\hline \multirow{3}{*}{$\begin{array}{l}\text { PMR } \\
\text { level }\end{array}$} & \multirow{2}{*}{\multicolumn{2}{|c|}{ Before treatment }} & \multicolumn{8}{|c|}{ After application of BTA } \\
\hline & & & \multicolumn{2}{|c|}{3 weeks } & \multicolumn{2}{|c|}{8 weeks } & \multicolumn{2}{|c|}{16 weeks } & \multicolumn{2}{|c|}{6 months } \\
\hline & Group I & Group II & Group I & Group II & Group I & Group II & Group I & Group II & Group I & Group II \\
\hline 0 & 0 & 0 & 13 & 9 & 22 & 10 & 1 & 1 & 0 & 0 \\
\hline 1 & 0 & 0 & 14 & 4 & 5 & 3 & 4 & 8 & 1 & 0 \\
\hline $1+$ & 2 & 1 & 1 & 1 & 1 & 1 & 4 & 4 & 1 & 1 \\
\hline 2 & 12 & 4 & 0 & 0 & 0 & 0 & 16 & 1 & 14 & 6 \\
\hline 3 & 14 & 9 & 0 & 0 & 0 & 0 & 3 & 0 & 12 & 7 \\
\hline 4 & 0 & 0 & 0 & 0 & 0 & 0 & 0 & 0 & 0 & 0 \\
\hline Total & 28 & 14 & 28 & 14 & 28 & 14 & 28 & 14 & 28 & 14 \\
\hline $\begin{array}{l}\text { Pearson } \\
\left(\chi^{2}\right) \text { test }\end{array}$ & $\begin{array}{l}\text { Significa } \\
\text { (before a } \\
\text { treatmen }\end{array}$ & d after & $*$ & $*$ & $*$ & $*$ & $*$ & $*$ & ns & ns \\
\hline
\end{tabular}

ns $-P>0.05 ;{ }^{*} P<0.001$

PMR - Passive Motion Resistance; MAS - Modified Ashworth Scale; BTA - Botulinum toxin type A

\section{DISCUSSION}

With respect to the recommendations given by the International Committee for the BTA therapy ${ }^{2}$, in our study the effects of the BTA treatment and physical therapy were estimated by the measurement of PMR as a local response and by the estimation of functional motoric levels as a qualitative category. In previous studies, the effects of BTA treatment were estimated by the follow-up of active and passive movements of the joints on affected limbs as objective parameters ${ }^{16-20}$. However, we question the objectivity of such measurement, particularly active movement in younger children (the study sample), mainly due to the poor cooperation with the child during the examination. For this reason, we decided to measure passive motion resistance levels in the evaluated population, since spasticity directly conditions movement range in joints. From the results we pointed out that BTA in CP treatment 
Table 4. Estimation of functionality degree (GMFCS) in evaluated group of patients before and after BTA application.

\begin{tabular}{|c|c|c|c|c|c|c|c|c|c|c|c|c|c|c|c|}
\hline \multirow[b]{3}{*}{$\begin{array}{c}\text { GMFCS } \\
\text { level }\end{array}$} & \multirow{2}{*}{\multicolumn{3}{|c|}{ Before treatment }} & \multicolumn{12}{|c|}{ After application of BTA } \\
\hline & & & & \multicolumn{3}{|c|}{3 weeks } & \multicolumn{3}{|c|}{8 weeks } & \multicolumn{3}{|c|}{16 weeks } & \multicolumn{3}{|c|}{6 months } \\
\hline & ڤ్రి & $\begin{array}{l}= \\
\stackrel{O}{O} \\
\stackrel{0}{0} \\
\stackrel{0}{U}\end{array}$ & 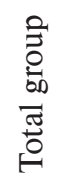 & 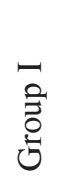 & 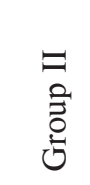 & 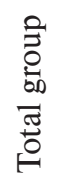 & 节 & 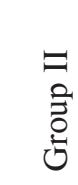 & 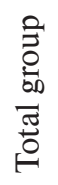 & 苛 & 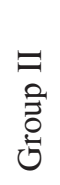 & 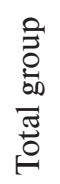 & 节 & 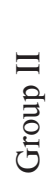 & 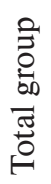 \\
\hline I & 1 & 2 & 3 & 2 & 3 & 5 & 3 & 4 & 7 & 5 & 7 & 12 & 2 & 4 & 6 \\
\hline II & 5 & 6 & 11 & 6 & 5 & 11 & 8 & 5 & 13 & 7 & 3 & 10 & 7 & 6 & 13 \\
\hline III & 10 & 3 & 13 & 8 & 3 & 11 & 5 & 2 & 7 & 4 & 1 & 5 & 7 & 1 & 8 \\
\hline Total & 16 & 11 & 27 & 16 & 11 & 27 & 16 & 11 & 27 & 16 & 11 & 27 & 16 & 11 & 27 \\
\hline $\begin{array}{l}\text { Pearson } \\
\left(\chi^{2}\right) \text { test }\end{array}$ & $\begin{array}{l}\text { Signi } \\
\text { and a }\end{array}$ & $\begin{array}{l}\text { ince } \\
\text { tre }\end{array}$ & $\begin{array}{l}\text { efore } \\
\text { hent) }\end{array}$ & ns & $\mathrm{ns}$ & ns & $\mathrm{ns}$ & ns & $*$ & $* *$ & $* *$ & $* *$ & ns & ns & ns \\
\hline
\end{tabular}

ns $-P>0.05 ;{ }^{*} P<0.05 ;{ }^{*} * P<0.001$

GMFCS - Gross Motor Function Classification System; BTA - Botulinum toxin type A

Table 5. Total GMFM score in evaluated groups of patients before and after BTA application.

\begin{tabular}{cllcc}
\hline Total GMFM score & Time of evaluation & & Mean value and SD & 95\% CI \\
\hline \multirow{2}{*}{$\begin{array}{c}\text { Group I } \\
\text { N=16 }\end{array}$} & Before treatment & & 67.76 SD 4.74 & $65.92-69.60$ \\
\cline { 2 - 5 } & After application of BTA & 3 weeks & 73.01 SD 4.24 & $71.36-74.64$ \\
& & 8 weeks & 75.06 SD 5.20* & $73.04-77.08$ \\
& & 16 weeks & 78.09 SD 5.48** & $76.96-80.21$ \\
Group II & Before treatment & 6 months & 70.89 SD 5.14 & $68.90-72.89$ \\
\cline { 2 - 5 } N=11 & After application of BTA & 3 weeks & 83.12 SD 3.55 & $81.07-85.17$ \\
& & 8 weeks & 87.98 SD 2.65* & $85.45-89.51$ \\
& & 16 weeks & 91.68 SD 2.38** & $89.30-93.05$ \\
& & 6 months & 81.06 SD 2.99 & $79.64-83.09$ \\
\hline
\end{tabular}

${ }^{*} P<0.05 ;{ }^{* *} P<0.01 * * * P<0.001$

GMFM - Gross Motor Function Measure; BTA - Botulinum toxin type A

is effective in lowering the PMR levels of affected muscles on lower limbs. The results correlate with previous similar reports ${ }^{21-23}$. In these studies measurement of spasticity, including PMR, was done using the method and in the same way as in our study by MAS, and such parameter of the evaluated study sample was presented as mean, referring to non qualitative characteristics. Therefore the results of this study were presented by the trend of the distribution value that is assumed to be more illustrative of findings presentation. One dominant characteristics of spastic CP type is walking disbalance that is primarily caused by the spasm of the affected muscles of the lower limbs. We demonstrated in our study that there is statistically significant decline in PMR levels for all evaluated muscles after 3 weeks from the beginning of the treatment in both groups and such significance persisted through the 16 weeks of treatment. In the period between 16 weeks to 6 months from the beginning of therapy there was no significant decline in PMR levels but there was still a distribution trend to lower PMR values. From 12 limbs with adductors spasm that were given the mark 3 for PMR level, after 6 months of treatment, 9 of them remained with the same PMR level. Regarding gastrocnemius muscle, of 23 limbs that were given the mark 3 for PMR level, 19 remained with same mark after 6 months of treatment. Functional measures are one of the most important parameters for the estimation of the BTA therapy in children with CP. It is important to underline the key question regarding the BTA therapy should be: would there be changes in motor-functional levels after the BTA treatment? Therefore, as standardized system for the classification of motoric functions in children with $\mathrm{CP}$ age between 1-12 years we used GMFCS (ref. ${ }^{14}$ ). It is designed a 5 level scale and reflects differences in functional and motor status of children during regular activities with special emphasis on sitting and walking. It has been noticed that GMFCS 
could be used for children of different ages to describe gross motor function ${ }^{2}$. Analyzing the age structure of $\mathrm{CP}$ children that were included in BTA treatment, significant variations were noticed in previous studies. It was noticed that younger children with I and II functional levels on GMFCS scale had higher consistent improvement, while older CP children with III and IV functional levels on the GMFCS scale had non significant improvements. One possible explanations could be the fact that children with moderate to severe physical limitations have lower potential for motoric functions improvement, with particular group at IV and V levels on the GMFCS scale, where limitation factor is contractures ${ }^{24,25}$. Our results were consistent with previous reports, pointing to the increase in motoric functions since the followed-up sample consisted of CP patients with functional levels from I to III. We demonstrated that there was a significant improvement in functional motoric status particularly after 16 weeks of treatment $(P<0.001)$ (Table 4$)$. The probable explanation for this is that children with $\mathrm{CP}$ have adopted $\mathrm{ab}$ normal motor patterns. Therefore, regardless of lowering the muscle tonus and increase in movements range, the adopted pathological motoric scheme is hardly corrected. The main role in the formation of normal patterns of motoric function rests on physical treatment, while the BTA treatment makes to some degree easier implementation of such treatment. Thus physical therapy is a necessary part of treatment in children with CP after BTA, as has been supported by several studies ${ }^{2,26,27}$. After 6 months from the beginning of the BTA, physical therapy and orthoses, there was no significant difference in functional improvement, but there was a greater distribution of participants with I and II functional levels on the GMFCS scale. Thus, it can be concluded that for children with $\mathrm{CP}$, with mild to moderate levels of motoric functional disturbances classification, improvement after BTA, physical therapy and orthoses is expected. The advantage of GMFCS beside categorization of child's functional mobility is that it can be used for estimating whether a child should be referred for hip dysplasia radiographic screening ${ }^{26}$. We demonstrated that there was significant increase in GMFM scores after 8 and 16 weeks from the application of BTA in both groups of patients. It is also shown that GMFM score was higher even after 6 month from the beginning of treatment, although without statistical significance, leading to the assumption that these patients maintain the practice certain adopted motoric functions that were gained during the course of physical therapy. Further, our study found that the trend of lowest PMR values for all muscles that were evaluated was between 3 and 8 weeks after the BTA in both groups. It should be noticed that even though there was gradual increase in PMR values after 8 weeks from BTA there was increase in GMFM score in both groups. Such findings suggest that botulinum toxin has great significance for the reduction of PMR, while for the motion skills acquisiton the longer period of time is needed, where physical therapy is considered as significant factor. In our study there were no side effects after BTA. Three patients were found to have infection of upper respiratory tract after 2 weeks from BTA application. Such symptomatology is typical in pediatric population, and probably unconnected to BTA (ref. ${ }^{2,28}$ ). There are several limitations in this study: the absence of placebo control group for ethical reasons in younger children. Further, the number of participants implies the necessity of further studies that will evaluate further functional and overall outcome of patients with spastic CP after administration of BTA. The implementation of MAS even though it is not considered reliable, was justified by the fact that younger children from our study were not considered confident for cooperation regarding active participation of proposed tasks, therefore passive motion resistance was assumed to be more reliable with the triplicate measurement of 3 experienced physiotherapists (one measurement per one physiotherapist) and supervision of qualified board certified physiatrist with experience in performing such functional tests. The GMFCS is not an outcome measure for $\mathrm{CP}$, but this test is reliable, valid and clinically relevant particularly concerning the management of $\mathrm{CP}$ (ref. ${ }^{2}$ ). In conclusion, administration of BTA treatment in children with $\mathrm{CP}$ is followed by reduction in PMR and improvement in functional motoric status of these patients.

\section{CONFLICT OF INTEREST STATEMENT}

Author's conflict of interest diclosure: None of the authors has any proprietary interest.

\section{REFERENCES}

1. Rosenbaum P, Paneth N, Leviton A, Goldstein M, Bax M. Definition and Classification Document, in The Definition and Classification of Cerebral Palsy (Ed Baxter P). Dev Med Child Neurol (Suppl) 2007;49:8-14

2. Love SC, Novak I, Kentish M, Desloovere K, Heinen F, Molenaers G, O'Flaherty S, Graham HK; Cerebral Palsy Institute. Botulin toxin assessment, intervention and after-care for lower limb spasticity in children with cerebral palsy: international consensus statement. Eur J Neurol 2010;17(Suppl. 2):9-37.

3. Watson L, Blair E, Stanley FJ. Report of the Western Australian Cerebral Palsy Register to Birth year 1999. Perth: Telethon Institute for Child Health Research; 2006.

4. Ziv I, Blackburn N, Rang M, Koreska J. Muscle growth in normal and spastic mice. Dev Med Child Neurol 1984;26:94-9.

5. Zwick EB, Leistritz L, Milleit BVS, Zwick G, Galicki M, Witte HGS. Classification of equinus in ambulatory children with cerebral palsydiscrimination between dynamic tightness and fixed contractures. Gait Posture 2004;20:273-9.

6. Graham HK. Absence of reference to progressive musculoskeletal pathology in definition of cerebral palsy. Dev Med Child Neurol 2006;48:78-9.

7. Van der Krogt MM, Doorenbosch CA, Becher JG, Harlaar J. Dynamic spasticity of plantar flexor muscles in cerebral palsy gait. J Rehabil Med 2010;42:656-63.

8. Barnes M, Johnson G. Upper Motor Neurone Syndrome and Spasticity. Cambridge: Cambridge University Press; 2008.

9. Dolly JO, Aoki KR. The structure and mode of action of different botulinum toxins. Eur J Neurol Suppl 2006;13:1-9.

10. Nestor MS, Ablon GR. Duration of Action of AbobotulinumtoxinA and OnabotulinumtoxinA: A Randomized, Double-blind Study Using a Contralateral Frontalis Model. J Clin Aesthet Dermatol 2011;4:43-9.

11. American Academy of Neurology. AAN classification of evidence for therapeutic intervention. 2004. Available from: http://www. neurology.org (accessed 23/January/ 2009) 
12. Assessment of spasticity, part I in: Cornerstone therapy education Accessed on line October 5, 2005. Availble from: http://www.cornerstoneceu.com/spasticityassessment.htm

13. Multu A, Livanelioglu A, Gunel MK. Reliability of Ashworth and Modifier Ashworth scales in children with spastic cerebral palsy. BMC Musculoskelet Disord 2008;9:44.

14. Rosenbaum PL, Palisano RJ, Bartlett DJ, Galuppi BE, Russell DJ. Development of the Gross Motor Function Classification System for cerebral palsy. Dev Med Child Neurol 2008;50:249-53.

15. Lundkvist Josenby A, Jarnlo GB, Gummesson C, Nordmark E. Longitudinal construct validity of the GMFM-88 total score and goal total score and the GMFM-66 score in a 5-year follow-up study. Phys Ther 2009;89:342-350.

16. Tedroff K, Löwing K, Haglund-Akerlind $Y$, Gutierrez-Farewik E, Forssberg $\mathrm{H}$. Botulinum toxin A treatment in toddler with cerebra palsy. Acta Paediatr 2010;99:1156-62.

17. Kaishou $X$, Tiebin $Y$, Jianning M. A randomized controlled trial to compare two botulinum toxin injection techniques on the functional improvement of the leg of children with cerebral palsy. Clin Rehabil 2009;23:800-11.

18. Hu GC, Chuang YC, Liu JP, Chien KL, Chen YM, Chen YF. Botulinum toxin (Dysport) treatment of the spastic gastrocnemius muscle in children with cerebral palsy: a randomized trial comparing two injection volumes. Clin Rehabil 2009;23:64-71.

19. Sätilä H, Pietikäinen $T$, lisalo $T$, Lehtonen-Räty $P$, Salo $M$, Haataja $R$, Koivikko M, Autti-Rämö I. Botulinum toxin type $A$ injections into the calf muscles for treatment of spastic equinus in cerebral palsy: a randomized trial comparing single and multiple injection sites. Am J Phys Med Rehabil 2008;87:386-94.

20. Koman LA, Mooney JF 3 rd, Smith BP, Walker F, Leon JM. Botulinum toxin type A neuromuscular blockade in the treatment of lower extremity spasticity in cerebral palsy: a randomized, double-blind, placebo-controlled trial. BOTOX Study Group. J Pediatr Orthop 2000;20:108-15.
21. Baker R, Jasinski M, Maciag-Tymecka I, Michalowska-Mrozek J, Bonikowski M, Carr L, MacLean J, Lin JP, Lynch B, Theologis T, Wendorff J, Eunson P, Cosgrove A. Botulinum toxin treatment of spasticity in diplegic cerebral palsy: a randomized, double-blind, placebo-controlled, dose-ranging study. Dev Med Child Neurol 2002;44:666-75.

22. Wang Y, Gao B. A dose-response relationship research on botulinum toxin type A intramuscular injections of lower extremity spasticity in children with cerebral palsy. Childs Nerv Syst 2008;24:545-7.

23. Bjornson K, Hays R, Graubert C, Price R, Won F, McLaughlin JF, Cohen M. Botulinum toxin for spasticity with cerebral pals: a comprehensive evaluation. Pediatrics 2007;120:49-58.

24. Scholtes VA, Dallmeijer AJ, Knol DL, Speth LA, Maathuis CG, Jongerius $\mathrm{PH}$, Becher JG. The combined effect of lower-limb multilevel botulinum toxin type $A$ and comprehensive rehabilitation on mobility in children with cerebral palsy: a randomized clinical trial. Arch Phys Med Rehabil 2006;87:1551-8.

25. Moore AP, Ade-Hall RA, Tudur Smith C, Rosenbloom L, Walsh HP, Mohamed K, Williamson PR. Two-year placebo-controlled trial of botulinum toxin A for leg spasticity in cerebral palsy. Neurology 2008;71:122-8.

26. Damiano DL, Alter KE, Chambers H. New clinical and research trends in lower extremity management for ambulatory children with cerebral palsy. Phys Med Rehabil Clin N Am 2009;20:469-91.

27. Cernak K, Stevens V, Price R, Shumway-Cook A. Locomotor training using body- weight support on a treadmill in conjunction with ongoing physical therapy in a child with cerebral palsy. Phys The 2008;88:88-97.

28. Dimitrijević L, Stanković I, Zivković V, Mikov A, Colović H, Janković I. Botulinum toxin type $A$ for the treatment of spasticity in children with cerebral palsy. Vojnosanit Pregl 2007;64:513-8. 